\title{
Individual Differences in Cerebral Blood Flow in Area 17 Predict the Time to Evaluate Visualized Letters
}

\section{Citation}

Kosslyn, Stephen Michael, William L. Thompson, Irene J. Kim, Scott L. Rauch, and Nathaniel M. Alpert. 1996. Individual differences in cerebral blood flow in area 17 predict the time to evaluate visualized letters. Journal of Cognitive Neuroscience 8(1): 78-82.

\section{Published Version}

doi:10.1162/jocn.1996.8.1.78

\section{Permanent link}

http://nrs.harvard.edu/urn-3:HUL.InstRepos:3595965

\section{Terms of Use}

This article was downloaded from Harvard University's DASH repository, and is made available under the terms and conditions applicable to Other Posted Material, as set forth at http:// nrs.harvard.edu/urn-3:HUL.InstRepos:dash.current.terms-of-use\#LAA

\section{Share Your Story}

The Harvard community has made this article openly available.

Please share how this access benefits you. Submit a story.

\section{Accessibility}




\title{
Individual Differences in Cerebral Blood Flow in Area 17 Predict the Time to Evaluate Visualized Letters
}

\author{
Stephen M. Kosslyn \\ Harvard University and Massachusetts General Hospital \\ William L. Thompson and Irene J. Kim \\ Harvard University
}

Scott L. Rauch and Nathaniel M. Alpert

Massachusetts General Hospital

\begin{abstract}
Sixteen subjects closed their eyes and visualized uppercase letters of the alphabet at two sizes, as small as possible or as large as possible while remaining "visible." Subjects evaluated a shape characteristic of each letter (e.g., whether it has any curved lines), and responded as quickly as possible. Cerebral blood flow was normalized to the same value for each subject, and relative blood flow was computed for a set of regions of interest. The mean response time for each subject in the task was regressed onto the blood flow values. Blood flow in area
\end{abstract}

\section{INTRODUCTION}

The "imagery debate" of the 1970 s and 1980 s focused on the question of whether visual mental images rely on a representation that depicts information (for a review, see Kosslyn, 1994). Behavioral data proved inadequate to implicate such representations, and thus it was very important that topographically mapped parts of the occipital lobe later were reported to be activated during imagery (e.g., see Damasio et al., 1993; Kosslyn et al., 1993; Kosslyn et al., 1995; Le Bihan et al., 1993; Menon et al., 1993). These areas preserve the (approximate) spatial structure of the retina, and hence depict information. Moreover, when these areas are damaged, visual imagery is impaired (e.g., see Farah, Soso, \& Dasheiff, 1992). Recently, however, two laboratories have reported that they do not observe activation in the topographically organized areas of the occipital lobe during visual mental imagery (for a review, see Roland \& Gulyas, 1994). Although there are numerous possible accounts for this null result, which rest on specific features of the experimental and baseline tasks (Kosslyn et al., 1995), there is another possibility: widespread individual differences. Indeed, the two functional magnetic resonance imaging studies (Menon et al., 1993; Le Bihan et al., 1993) both

17 was negatively correlated with response time $(r=-0.65)$, as was blood flow in area $19(r=-0.66)$, whereas blood flow in the inferior parietal lobe was positively correlated with response time $(r=0.54)$. The first two effects persisted even when variance due to the other correlations was removed. These findings suggest that individual differences in the activation of specific brain loci are directly related to performance of tasks that rely on processing in those loci.

report such individual differences. If such differences are widespread enough, then due to the luck of the draw null results will occasionally be obtained when relatively small numbers of subjects are tested.

The mere finding of individual differences in the ability to activate the topographically organized parts of the occipital lobe during imagery would be of limited interest. A key question is whether there are functional consequences of such processing. If not, then such activation could be "epiphenomenal," and would not implicate a functional representation. Goldenberg et al. (1989) report single photon emission computed tomography (SPECT) results that lead us to expect a functional relationship between such activation and information processing; they found that some subjects using imagery to judge the correctness of sentences had greater blood flow in the inferior occipital lobe. This technique, however, has very limited spatial resolution, and thus we cannot be certain that the activation reflects processing in parts of the brain known to be topographically organized. We report a new set of analyses of positron emission tomography (PET) findings that demonstrate that less blood flow in a topographically organized area is correlated with poorer performance on an imagery task. 


\section{METHOD}

The data reported here were reported previously by Kosslyn et al. (1993, Experiment 3). We briefly summarize key aspects of the method and procedure here; for further details, see Kosslyn et al. (1993).

\section{Subjects}

Sixteen right-handed men volunteered to participate as paid subjects; most of the subjects were college or medical students. The subjects' mean age was 22 years, 10 months (range 18;9-32;11).

\section{Materials}

The subjects heard a series of auditory stimuli. One set signaled four possible judgments the subjects were to make about visualized letters of the alphabet: These cues and associated judgments were (1) "all straight," which required the subjects to decide whether the letter has any curved lines or is composed solely of straight (including diagonal) lines; (2) "symmetrical," which required the subjects to decide whether the letter is left/right symmetrical; (3) "straight side," which required the subjects to decide whether the letter has at least one straight (i.e., vertical or horizontal) line that extends the entire length of one of its four sides; and (4) "two terminators," which required the subjects to decide whether the letter has exactly two terminators (end points that do not meet any other lines). Four sets of cue words were used to signal each type of judgment; the words were (1) "all straight," (2) "symmetrical," (3) "straight side," and (4) "two terminators."

The names of all 26 letters of the alphabet were recorded, each of which was followed by one of the cues. Each cue appeared equally often, and the correct response for each type of judgment was equally often "yes" and "no." Twenty letters were used for each type of judgment, and each type of judgment was paired only once with each letter. Each trial was recorded in the following sequence: A 500 -msec tone signaled the beginning, followed by a 500-msec delay; the name of a letter was then read, followed 4 sec later by one of the cues. A total of 80 trials were prepared. No more than three responses of the same type could appear in sequence. Two sets of 16 practice trials were also prepared, which were identical, except for the order of the stimuli; these trials used the names of digits, rather than letters, as stimuli.

\section{Task Procedure}

The subjects first read instructions that explained the four judgments, which were illustrated using examples of random figures that did and did not correspond to the criterion. The cue words were explained, and the sub- jects were told that they would soon be asked to listen to the names of letters of the alphabet. Their task was to visualize the uppercase version of the letter, hold the image, and then "see" whether the cued characteristic was present in the image. The subjects were told that they should keep their eyes closed during the entire experiment, that they should retain the mental image of the appropriate letter until hearing one of the cues, and that they should respond as quickly and accurately as possible after "looking" at the imaged letter. In one block of trials the subjects were asked to visualize the letters as small as possible, and in another they were asked to visualize them as large as possible without seeming to overflow the image.

The subjects next were positioned in the PET scanner, and then were given the practice trials; the subjects were told that they would be evaluating numbers (no letters). They were told that a tone would signal the beginning of a trial, which would shortly be followed by the name of a digit. They were asked to visualize the stimulus in a standard font, at either the large or small size (depending on the block); half the subjects began by visualizing stimuli at the small size and then received a block in which they visualized at the large size, and vice versa for the other half of the subjects. Upon hearing the judgment cue, the subjects were to "look" for that characteristic on the visualized stimulus; if it was present they were to press the pedal under their right foot, and if it was not present they were to press the pedal under their left foot. The subjects were told to respond as quickly and accurately as possible. Five hundred milliseconds after the subject responded, a new trial began. The test trials were the same format as the practice trials, but subjects visualized uppercase letters, in a "typical font," instead of numbers. The computer that delivered the stimuli also recorded the responses and response times.

\section{PET Procedure}

The subjects began the first block of trials $30 \mathrm{sec}$ before ${ }^{15} \mathrm{O}$ was administered, and they continued performing the task for approximately $1.5 \mathrm{~min}$. Approximately $5 \mathrm{~min}$ after the first block, the subjects were told at which size they were to visualize the letters in the following block. They then received the practice trials again, in the other order (see Kosslyn et al., 1993 for details as to the PET procedure).

\section{RESULTS}

We began by normalizing cerebral blood flow (rCBF) for each subject to $50 \mathrm{ml} / \mathrm{min} / 100 \mathrm{~g}$ across the whole brain to allow us to compare activation within a region of a single slice as well as across slices. For each individual brain, regions of interest were drawn around all of the areas that were typically activated in the imagery experi- 
ments reported by Kosslyn et al. (1993). The areas we examined were 17, 19, middle temporal gyrus, fusiform gyrus, inferior parietal, superior parietal, precentral gyrus, superior temporal, angular gyrus, middle frontal, and dorsolateral prefrontal areas. To determine the regions of interest, we drew a circle with a 5-pixel radius around the coordinates of the most significantly activated pixel in each area in the images created by averaging over subjects. The areas were classified using the Talairach and Tournoux (1988) and Talairach et al. (1967) atlases; all classifications were consistent in both atlases. We next computed the blood flow, relative to the global mean, in each of these regions of interest (ROIs) for each subject. These data were treated as independent variables in forward stepwise multiple regression analyses.

The dependent variable in these analyses was mean response time for each subject. That is, we took the time to respond during the task, as the PET scan was conducted, for each trial. We considered response times only for trials on which the subject made a correct response ( $86 \%$ of the data), and treated as outliers response times greater than 2.5 times the mean of the appropriate cell for a given person; $7.8 \%$ of trials were discarded using this criterion.

Table 1 presents Pearson correlations between response times and blood flow in the 11 ROIs for all 16 subjects. As is evident, relative blood flow in area 17 was negatively correlated with response time, $r=-0.65, p=$ 0.006; this finding is illustrated in Figure 1. Thus, subjects who had less blood flow-relative to the global means of their brains-in area 17 responded more slowly in the letter-evaluation task. In addition, we found that area 19 was negatively correlated with response time, $r=-0.66$, $p=0.004$, and the inferior parietal region was positively correlated with response time $r=0.54, p=0.03$; these results are illustrated in Figure 2. We also found statisti-

Table 1. Pearson Correlations between Response Times and Blood Flow in 11 ROls for 16 Subjects

\begin{tabular}{lcc}
\hline & Correlation & $p$-Value \\
\hline RT, fusiform & -0.02 & 0.94 \\
RT, area 19 & -0.66 & 0.004 \\
RT, angular gyrus & 0.10 & 0.70 \\
RT, middic frontal & -0.05 & 0.85 \\
RT, inferior parietal & 0.54 & 0.03 \\
RT, superior parietal & -0.14 & 0.62 \\
RT, middle temporal & 0.03 & 0.92 \\
RT, superior temporal & -0.05 & 0.87 \\
RT, precentral gyrus & 0.28 & 0.31 \\
RT, DLPFC & -0.30 & 0.26 \\
RT, area 17 & -0.65 & 0.006 \\
\hline
\end{tabular}

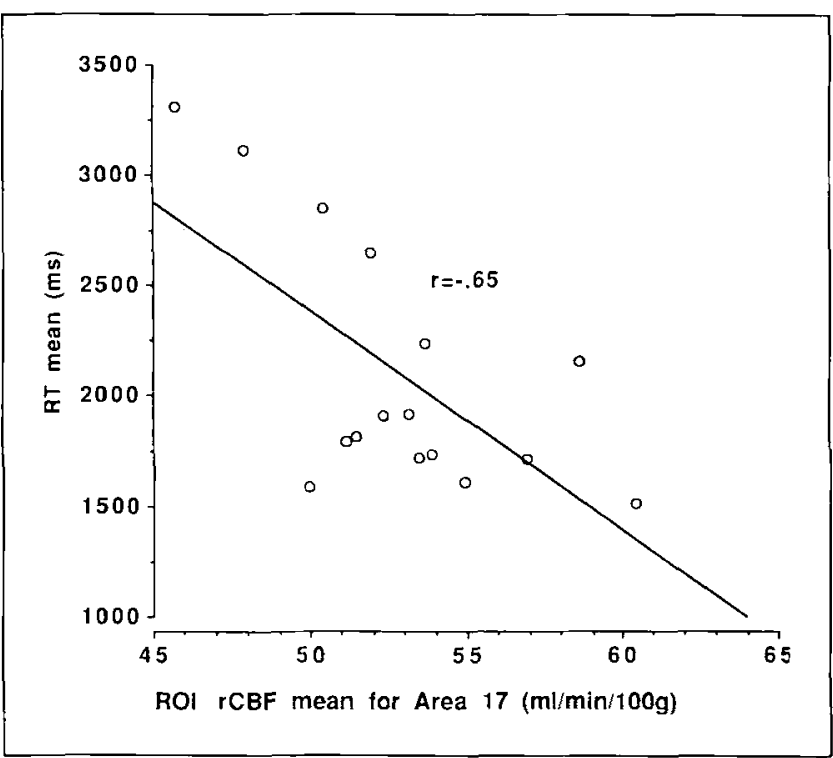

Figure 1. Response times for individual subjects plotted according to blood flow in area 17 relative to the global mean (which was set to a value of $50 \mathrm{ml} / \mathrm{min} / 100 \mathrm{~g}$ ).

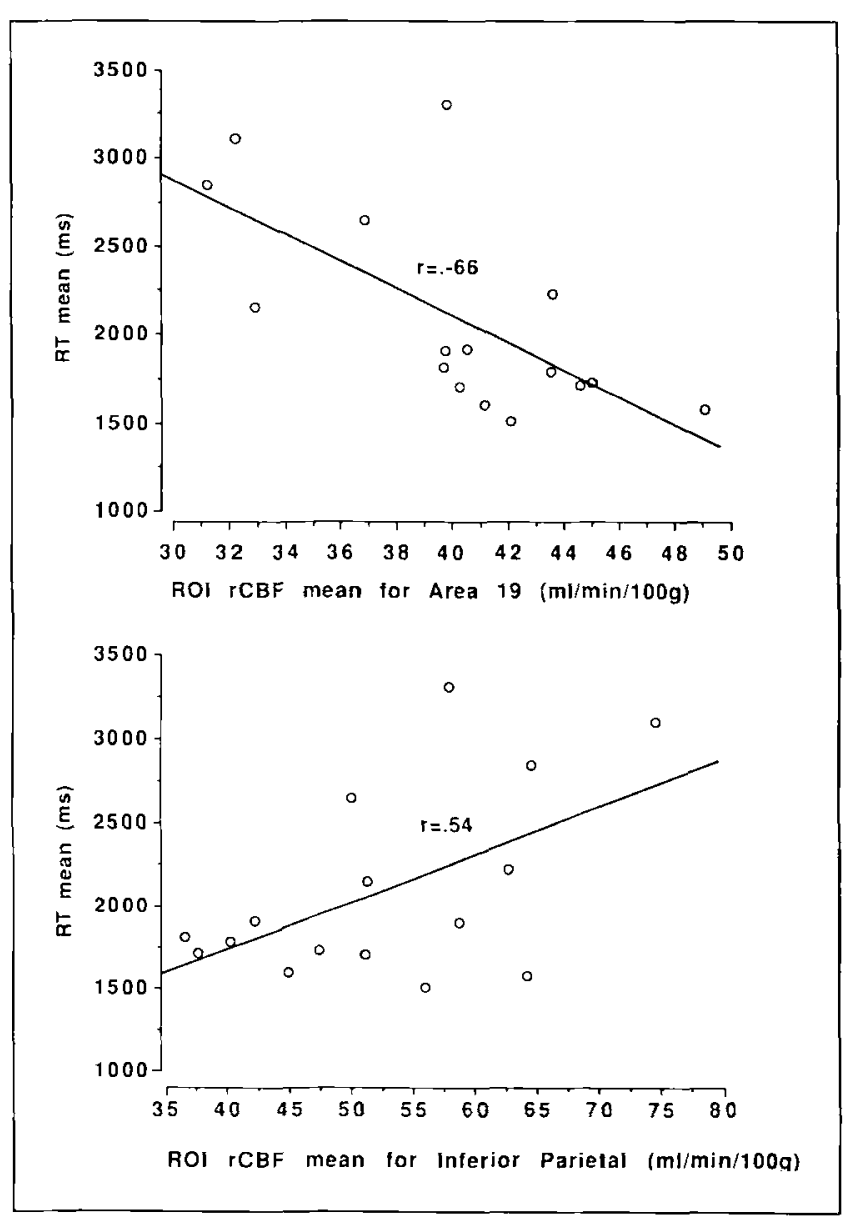

Figure 2. Top: Response times for individual subjects plotted according to blood flow in area 19 relative to the global mean (which was set to a value of $50 \mathrm{ml} / \mathrm{min} / 100 \mathrm{~g}$ ). Bottom: Response times for individual subjects plotted according to blood flow in the inferior parittal lobe relative to the global mean (which was set to a value of $50 \mathrm{ml} / \mathrm{min} / 100 \mathrm{~g}$ ). 
cally significant $(p<.05)$ correlations between bloud flow in these different areas. Specifically, we found correlations between flow in the superior temporal gyrus and fusiform and middle temporal gyri; between the angular gyrus and the fusiform, inferior parietal, precentral, and dorsolateral prefrontal areas; between the superior parietal area and dorsolateral prefrontal, midalle frontal, and area 17; and between the inferior parietal area and the precentral gyrus.

We next asked whether the relation between area 1 ? and response time could be an artifact of another correlation. As a preliminary investigation of this possibility. we performed a stepwise multiple regression analysis in which response times were regressed on the 11 Rols. (Note: because we are not interested in the total vari ance accounted for by the equation with all 11 independent variables, but rather only in the most important few predictors, this relatively large number of independent variables is not troublesome.) The correlation between blood flow in area 19 and response time en tered the equation first, and the correlation with area $1^{-}$ entered second; this partial corrclation predicted significant amounts of variance in the response times. $F(1,10)=21.85, p<0.01$, even after the contribution of blood flow in area 19 was removed. The third and final variable to enter was dorsolateral prefrontal cortex, $N(1$, $10)=6.92, \rho<0.05$, which was also negatively correlated with response time. Thus, after the contribution of areas 19 and 17 was removed, a significant negative relation between blood flow in prefrontal cortex and response time was revealed. The multiple correlation of the three variables with response time was 0.93 . Thus. approximately $87 \%$ of the variance in response times could be accounted by variations in blood flow in threc regions of the brain.

We next forced the measures of blood flow in area 19 and in dorsolateral prefrontal cortex into the equation first, and observed whether area 17 still predicted variance in response times. In fact, even with the contribution of the other areas factored out, blood flow in area 17 was still correlated with response times, $F(1,10)=$ $37.11, p<0.0001$. Note that in none of the regression analyses did blood flow in the inferior parietal lobe predict response time; the simple correlation between blood flow in this area and response time appears to have been a consequence of corrclations among the areas.

We next performed the identical analyses with error rates, instead of response times, as the dependent variable. These results are easy to summarize: blood tlow was not correlated with error rates. Indeed, only blood flow in the inferior parietal lobe had even a tendency to be correlated with error rates, $r=-0.445, p=0.084$. Blood flow in area 17 was not correlated with error rate, $r=$ $0.34, p>0.1$.

\section{DISCUSSION}

The result illustrated in Figure 1 is of central interest to the question we asked. Note two features of this result First, approximately $25 \%$ of the subjects either had average blood flow (relative to the global mean) or lessthan average blood flow in area 17 during visual imagery (when their eyes were closed). Thus, we have provided further evidence for substantial individual differences in the ability to activate topographically organized areas in the occipital lobe during visual mental imagery. Second. note that thosc subjects with the lowest blood flow were the ones who required the most time to perform the task. Note also that although we have fitted a linear regression line though these data, there may be a bimodall distribution: Some of the subjects with near-average blood flow in area $1^{7}$ were not particularly slow. It is possible that there is a threshold amount of activation that is necessary for good performance in this task, and once one has achieved this threshold times do not vary for different anounts of blood flow.

The large negative correlation with area I9 may reflect its role as an "associative memory structure" in this task. Not only must subjects access stored information about the structure of the letters to form the image (sec Kosilyn, 1994), but they must access the association between the cue and the specific judgment to be performed. In addition, the contribution of dorsolateral prefrontal cortex may reflect its rok in working memory." Holding the image in mind and evaluating it for a property of a shape clearly involves such processing (cf. Goldman-Rakic, 1987: Smith \& Jonides, 1994)

Finally, it is possible that the correlation between activation of area 17 and response time depends on the requirements of the imagery task. The letter-evaluation task we used here requires a moderate amount of spatial resolution. It is possible to design imagery tasks that require greater or lesser spatial resolution. For example. subjects coukd be asked to visualize texture patterns that included relatively high spatial frequencies or relatively low spatial frequencies, and then woukl be required to classify the textures in various ways based on these images. It would be of interest to discover whether the correlation between blood flow in area 17 and performance depends on the level of spatial resolution required for the task, and whether people who perform high-resolution tasks poorly also perform low-resolution tasks poorly:

\section{Acknowledgments}

This research was supported by ONR Girant No(0)1 1-9) - J-1 2+3 awarded to the first and last atthors. This experinent was approved by the larvard University and Massachusetts (iencral Hospital Institutional Review Boards. and all subjects gave informed consent. We wish to thank Avis Loring and steve Weise for their techmical alssistance in testing the subjects, and Rob 
McPeek and David Baker for their help in developing the software to present stimuli.

Requests for reprints should be sent to S. M. Kosslyn, 832 William James Hall, 33 Kirkland Street, Cambridge, MA 02138.

\section{REFERENCES}

Damasio, H., Grabowski, T. J., Damasio, A., Tranel, D., BolesPonto, L., Watkins, G. L., \& Hichwa, R. D. (1993). Visual recall with eyes closed and covered activates early visual cortices. Society for Neuroscience Abstracts, Vol. 19 , Part 2, p. 1603

Farah, M. J., Soso, M. J., \& Dasheiff, R. M. (1992). Visual angle of the mind's eye before and after unilateral occipital lobectomy. Journal of Experimental Psychology: Human Percetion and Performance, 18, 241-246.

Friston, K. J., Frith, C. D., Liddle, P. F., \& Frackowiak, R. S. J. (1991). Comparing functional (PET) images: The assessment of significant changes. Journal of Cerebral Blood Flow and Metabolism, 11, 690-699.

Goldenberg, G., Podreka, I., Steiner, M., Willmes, K., Suess, E., \& Deecke, L. (1989). Regional cerebral blood flow patterns in visual imagery. Neuropsycbologia, 27, 641-664.

Goldman-Rakic, P. S. (1987). Circuitry of primate prefrontal cortex and regulation of behavior by representational knowledge. In F. Plum \& V. Mountcastle (Eds.), Handbook of physiology, Section 1: The nervous system, Volume 5: Higher functions of the brain (pp. 373-417). Bethesda, MD: American Physiological Society.

Kosslyn, S. M. (1994). Image and brain: The resolution of the imagery debate. Cambridge, MA: MIT Press.
Kosslyn, S. M., Alpert, N. M., Thompson, W. L., Maljkovic, V., Weise, S. B., Chabris, C. F., Hamilton, S. E., Rauch, S. L.. \& Buonanno, F. S. (1993). Visual mental imagery activates topographically organized visual cortex: PET investigations. Journal of Cognitive Neuroscience, 5, 263-287.

Kosslyn, S. M., Thompson, W. L., Kim, I. J. and Alpert, N. M. (1995). Topographical representations of mental images in primary visual cortex. Nature, 378, 496-498.

Le Bihan, D., Turner, R., Zeffiro, T. A., Cuénod, C. A., Jezzard, P, \& Bonnerot, V. (1993). Activation of human primary visual cortex during visual recall: A magnetic resonance imaging study. Proceedings of the National Academy of Sciences U.S.A., 5, 11802-11805.

Menon, R., Ogawa, S., Tank, D. W., Ellermann, J., Merkele, H., \& Ugurbil, K. (1993). Visual mental imagery by functional brain MRI. In D. Le Bihan, R. Turner, M. Mosley, \& J. Hyde (Eds.), Functional MRI of the brain: A worksbop presented by the Society of Magnetic Resonance in Medicine and the Society for Magnetic Resonance Imaging Arlington, VA: Society of Magnetic Resonance in Medicine.

Roland, P. E., \& Gulyas, B. (1994). Visual imagery and visual representation. Trends in Neurosciences, 17, 281-287.

Smith, E. E., \& Jonides, J. (1994). Working memory in humans: Neuropsychological evidence. In M. S. Gazzaniga (Ed.), The cognitive neurosciences (pp. 1009-1020). Cambridge, MA: MIT Press.

Talairach, J., Szikla, G., Tournoux, P., Prossalentis, A., Bordas-Ferrer, M., Covello, L., Iacob, M., \& Mempel, E. (1967). Atlas of stereotactic anatomy of the telencephalon. Paris: Masson.

Talairach, J., \& Tournoux, P. (tr. M. Rayport). (1988). Co-planar stereotaxic allas of the buman brain. New York: Thieme. 


\section{This article has been cited by:}

1. B. B. Biswal, D. A. Eldreth, M. A. Motes, B. Rypma. 2010. Task-Dependent Individual Differences in Prefrontal Connectivity. Cerebral Cortex . [CrossRef]

2. Valérie Hubert, Hélène Beaunieux, Gaël Chételat, Hervé Platel, Brigitte Landeau, Fausto Viader, Béatrice Desgranges, Francis Eustache. 2009. Age-related changes in the cerebral substrates of cognitive procedural learning. Human Brain Mapping 30:4, 1374-1386. [CrossRef]

3. Valérie Hubert, Hélène Beaunieux, Gaël Chételat, Hervé Platel, Brigitte Landeau, Jean-Marie Danion, Fausto Viader, Béatrice Desgranges, Francis Eustache. 2008. The dynamic network subserving the three phases of cognitive procedural learning. Human Brain Mapping 28:12, 1415-1429. [CrossRef]

4. K. Prehn, I. Wartenburger, K. Meriau, C. Scheibe, O. R. Goodenough, A. Villringer, E. van der Meer, H. R. Heekeren. 2007. Individual differences in moral judgment competence influence neural correlates of socio-normative judgments. Social Cognitive and Affective Neuroscience 3:1, 33-46. [CrossRef]

5. Stephen M. Kosslyn, William L. Thompson. 2003. When is early visual cortex activated during visual mental imagery?. Psychological Bulletin 129:5, 723-746. [CrossRef]

6. Michael B. Miller, John Darrell Van Horn, George L. Wolford, Todd C. Handy, Monica Valsangkar-Smyth, Souheil Inati, Scott Grafton, Michael S. Gazzaniga. 2002. Extensive Individual Differences in Brain Activations Associated with Episodic Retrieval are Reliable Over TimeExtensive Individual Differences in Brain Activations Associated with Episodic Retrieval are Reliable Over Time. Journal of Cognitive Neuroscience 14:8, 1200-1214. [Abstract] [PDF] [PDF Plus]

7. Stephen M. Kosslyn, John T. Cacioppo, Richard J. Davidson, Kenneth Hugdahl, William R. Lovallo, David Spiegel, Robert Rose. 2002. Bridging psychology and biology: the analysis of individuals in groups. American Psychologist 57:5, 341-351. [CrossRef]

8. Turhan Canli, Zuo Zhao, John E. Desmond, Eunjoo Kang, James Gross, John D. E. Gabrieli. 2001. An fMRI study of personality influences on brain reactivity to emotional stimuli. Bebavioral Neuroscience 115:1, 33-42. [CrossRef]

9. K. M. O'Craven, N. Kanwisher. 2000. Mental Imagery of Faces and Places Activates Corresponding Stimulus-Specific Brain RegionsMental Imagery of Faces and Places Activates Corresponding Stimulus-Specific Brain Regions. Journal of Cognitive Neuroscience 12:6, 1013-1023. [Abstract] [PDF] [PDF Plus]

10. Isabelle Klein , Anne-Lise Paradis, Jean-Baptiste Poline, Stephen M. Kosslyn, Denis Le Bihan . 2000. Transient Activity in the Human Calcarine Cortex During Visual-Mental Imagery: An Event-Related fMRI StudyTransient Activity in the Human Calcarine Cortex During Visual-Mental Imagery: An Event-Related fMRI Study. Journal of Cognitive Neuroscience 12:supplement 2, 15-23. [Abstract] [PDF] [PDF Plus]

11. E. Mellet , N. Tzourio-Mazoyer , S. Bricogne , B. Mazoyer , S. M. Kosslyn , M. Denis . 2000. Functional Anatomy of High-Resolution Visual Mental ImageryFunctional Anatomy of High-Resolution Visual Mental Imagery. Journal of Cognitive Neuroscience 12:1, 98-109. [Abstract] [PDF] [PDF Plus]

12. Roberto Cabeza , Lars Nyberg . 2000. Imaging Cognition II: An Empirical Review of 275 PET and fMRI StudiesImaging Cognition II: An Empirical Review of 275 PET and fMRI Studies. Journal of Cognitive Neuroscience 12:1, 1-47. [Abstract] [PDF] [PDF Plus]

13. Tommi Raij . 1999. Patterns of Brain Activity during Visual Imagery of LettersPatterns of Brain Activity during Visual Imagery of Letters. Journal of Cognitive Neuroscience 11:3, 282-299. [Abstract] [PDF] [PDF Plus]

14. Manfred Spitzer, Thomas Kammer. 1996. Current Opinion in Psycbiatry 9:5, 352-363. [CrossRef]

15. Stephen M. Kosslyn, Giorgio Ganis, William L. ThompsonMental Imagery . [CrossRef] 